\title{
RETRACTED ARTICLE: Gas tungsten constricted arc welding (GTCAW) parameters optimization to attain maximum tensile strength in Ti-6Al-4V alloy sheets used in aero-engine components
}

\author{
V. Vaithiyanathan ${ }^{1} \cdot$ V. Balasubramanian ${ }^{1} \cdot$ S. Malarvizhi ${ }^{1} \cdot$ Vijay Petley $^{2} \cdot$ Shweta Verma $^{2}$
}

Received: 7 February 2019 / Accepted: 21 May 2019 / Published online: 27 May 2019

(c) Springer Nature Switzerland AG 2019

The editor has retracted this article [1] because it shows significant overlap with two other publications by the same authors without proper citation [2, 3].

V. Vaithiyanathan and V. Balasubramanian agreee to this retraction. S. Malarvizhi, Vijay Petley, and Shweta Verma have not responded to any correspondence from the publisher about this retraction.

[1] Vaithiyanathan, V., Balasubramanian, V., Malarvizhi, S. et al. Multiscale and Multidiscip. Model. Exp. and Des. (2019). https://doi.org/10.1007/s41939-019-00050-5
[2] Padmanaban G, Balasubramanian V. Transactions of Nonferrous metals society of China. (2011). https://doi. org/10.1016/S1003-6326(11)60738-3

[3] Subravel, V., Padmanaban, G., Balasubramanian, V., Indian Welding Journal, (2014).https://doi.org/10.22486/iwj. v47i4.141092

Electronic supplementary material The online version of this article (https://doi.org/10.1007/s41939-019-00050-5) contains supplementary material, which is available to authorized users.

V. Vaithiyanathan

vaithimfg@gmail.com

V. Balasubramanian

visvabalu@yahoo.com

S. Malarvizhi

jeejoo@rediffmail.com

Vijay Petley

petleyvijay@gmail.com

Shweta Verma

shweta@gtre.drdo.in

1 Department Of Manufacturing Engineering, Centre for Materials Joining \& Research (CEMAJOR),

Annamalai University, Annamalai Nagar, Chidambaram, Tamil Nadu 608002, India

2 Materials Group (MTG), Gas Turbine Research Establishment (GTRE), Bengaluru 560093, India 